\title{
Sommario
}

\section{Premessa $-\mathbf{V} \mathbf{I}$}

I. Introduzione - 1

1. Il manoscritto $753-3$

2. Le fonti: il Planctus veronese volgarizzamento del Planctus Magistrae Doloris - 6

3. La lingua del testo: considerazioni generali -13

4. La forma del testo $-\mathbf{1 5}$

5. Dal latino al volgare - 19

6. Motivi tradizionali nel Planctus veronese -23

II. Nota al testo $-\mathbf{2 7}$

III. Tavola degli omografi -29

IV. Planctus Magistrae Doloris - 31

V. Commento linguistico $-\mathbf{5 9}$

1. Grafia - 59

2. Vocalismo - 62

3. Consonantismo -71

4. Morfologia -79

5. Sintassi -93

VI. Glossario - 105

VII. Bibliografia -123 